\title{
Perceptions of the School Management Teams on the Continuous Professional Development of Information Communication Technology Educators: A Human Capital Development Analysis of a South African School
}

\author{
Edmore Mutekwe \\ Vaal University of Technology, Faculty of Human Sciences, South Africa \\ Email: edmorem@vut.ac.za
}

Doi:10.5901/mjss.2014.v5n27p931

Abstract

Continuous professional development (CPD) in the context of a school is the enhancement of educators' skills, academic qualifications and the up-skilling of their knowledge and competencies in the domains in which they operate. The purpose of this study is to explore how the CPD of ICT educators informs the achievement of the vision and mission of the school as a learning organization. The vision for this school where the study was conducted is to be the best performing and well sought after school in the province while its mission is to ensure that educators use ICT not only for administrative purposes but also as an important tool in the mediation of teaching and learning for a diversity of learners in the classroom. The data collection for this study was conducted using semi-structured individual interviews and observations with a total sample size of 10 ICT educators and members of the school management team (SMT) purposively sampled. The analysis of findings followed a thematic approach. Using the human capital development perspective as the lens for analysis the study was able to unmask the challenges endured by educators and the SMTs in their quest to improve learning outcomes in ICT. The qualitative case study design genre adopted for this study enabled the unmasking of challenges embedded in some school leadership approaches used by principals. Among these challenges or barriers are the ignorance of ICT educators to fully utilize computers to promote effective teaching and learning. The recommendations made from this study include is that school principals and or SMTS need to view themselves as coaches and adopt the game plan metaphor approach so that just as a coach has to plan strategies to mentor players to win the game, they also link and intertwine their leadership styles with a desire for effective organizational behaviour to make sure their team players (ICT educators) are fully prepared for the game plan, which implies ensuring CPD for successful ICT teaching and learning culminating in improved school effectiveness.

Keywords: organisational culture, school effectiveness, stakeholders, learning organisations

\section{Introduction}

The continuous professional development of educators is more than just the improvement and development of individual teachers. It transcends this and contributes towards the improvement of the school as a whole (Desimone, Smith \& Ueno (2006). Political discrepancies and social injustices by school leadership often lead to the problem of many unqualified and underqualified teachers in schools. Imperative to this and current to schools is the continuous professional development of educators in ICT, which reduces the digital divide that exists. It also develops the necessary computer skills that educators need to keep them abreast with the technological demands that exist among the learners and the technological devices readily available in schools. Further to this, evidence found in the literature and legislation on professional development demonstrates that both learners and educators benefit from the use of technology in the classroom. This argument is supported strongly by the goals of White Paper 7 on Education and Training, which demonstrates that teacher education is the main foundation of human resource and development. The major thesis advanced in this paper is that continuous teacher professional development is central to the organizational behaviour and development effective schools. In support of this view various literature sources and participants' views are drawn from. As a qualitative research study employing a case study, it is hoped that it generates in-depth data (Yin 2000) that reflects perceptions of not only the educators themselves but also other stakeholders such as SMTS, parents, learners, District and School Based Support Teams (DBST and SBST). Various authors, among them, Mestry, Bischoff and Hendriks (2009) and (Guskey 2000) maintain that organizations such as schools need to take into account the transformational educational legislative and policy innovations designed for post-apartheid South Africa to ensure schools become effective. 
According to the above mentioned authors, the agenda for education, namely to address the vision of the National Department of Education, which seeks to improve the culture of teaching and learning in schools cannot be realised unless and until the continuous professional development of educators is given top priority. For them, this human capital development perspective needs to be taken seriously if the organizational behaviour of educators is to promote school effectiveness. This human dimension of organizations (Owens, 2005) assumes that the continuous professional development of educators can be used as a mechanism to enhance and develop learners' knowledge and experiences in schools. The authors further maintain that the various school's stakeholders, Department of Education, Districts and School Based Support Teams, SMTs, parents, educators and the learners themselves need to understand that only if educators are professionally developed can school effectiveness become a reality as this will enable them meet their core business, to enhance the development of learner skills and abilities. Drawing their argument from the Integrated Quality Management Systems (IQMS) and how it can be used as a tool to measure the individual teacher development needs in public schools, Mestry, Harris \& Bischoff (2009) examine the policy, the Integrated Quality Management Systems IQMS, which is used as a programme for professional development of teachers in public schools and question the validity and reliability or effectiveness of the IQMS system by not foregrounding the importance of continuous educator professional development in improving school effectiveness. Among the key aspects of the professional development of educators advanced by the aforementioned authors is the view that for a school system to be effective, stakeholders that include SMTs have a shared responsibility to improve student learning outcomes. They also have a reciprocal responsibility to provide teachers with extended opportunities to build on what they already know (human capital) about effective learning and teaching (Mestry et al., 2009).

\section{Problem Statement}

In response to the revolutionary technological inventions and developments in educational institutions currently sweeping across the globe (Stein, Shepard \& Harris (2011) schools have to adopt cutting edge technology in their classrooms. Educators and school staff need to be empowered with skills, knowledge and competencies through CPD particularly in the use of ICT in the classroom. A large majority of educators in the educational institutions are products of colleges that did not integrate ICT in the curriculum of teacher training courses. Hence most educators lack the skills with some leaders being adamant to integrate ICT in their teaching and learning systems (Stein, et al., 2011). The knowledge and skills on the use of ICT in the classroom is of great importance for educators for them to effectively function within the continuous changing trends in education. While it is indisputable that ICT has brought new possibilities into the education sector, it is also correct to argue that not all educators in schools know what to do with the computers that some concerned organizations donate to them (National Department of Education, 2007). It is in this view that this paper argues for CPD programmes as a condition necessary and sufficient for effective schools of the $21^{\text {st }}$ century. The study sought answers to the following research questions.

\section{Research Questions}

Main research question: what perceptions do the SMTs hold regarding the continuous professional development of educators in ICT use in the classroom?

Sub-questions: what roles do SMTs play in the professional development of educators in ICT?; how does the SMT view the link between continuous professional development of educators and school effectiveness?

\section{Aim and Objectives of the Study}

The purpose of this study was to explore and unmask the views of educators and SMTs on the importance of CPD of ICT educators in the schools. In pursuit of this aims, the following objectives were formulated:

- To examine the SMTs' conceptions of continuous teacher professional Development in schools.

- To establish the role of SMTs in the continuous professional development of educators in schools.

- To identify the link that exists in CPD, organizational behaviour and school effectiveness.

- To identify conditions necessary for improved CPD of educators and school effectiveness 


\section{Literature Review}

The literature review for this study is conducted in line with the philosophy that the more one understands trends in the area not necessarily similar but related to her study, the more she is able to approach her study from an informed position (Nieuwenhuis, 2012). The theoretical framework guiding the study is the human dimension of schools as learning organizations as propounded by Owens (2005) and developed by others such as Desimone, Smith and Ueno (2006), Oscar, Mink and Owens (2000), Stein, Shepard and Harris (2011). The literature review for the study is thus guided by the following subheadings: theoretical framework for viewing the continuous professional development of educators, conceptualisations of continuous professional development of educators, and the role of leadership in the professional development of educators; the role of CPD on organizational behaviour and strategies for improving school effectiveness.

\subsection{Theoretical framework}

In discussing the theoretical framework adopted for this study, it is important to note that after 1975, organizational thought took a major turn away from such formal theorising, which emphasised the machinelike characteristics that many scholars believed underlay the ways in which organizations worked (Owens, 2005). This paradigm shift gravitated towards a markedly increased focus on the human dimensions of organizations. The shift was precipitated by forces such as the intellectual movement, which brought to the fore a new analysis of the fundamental concept of what an organization such as a school actually is. It is in this sense that the study adopted the human dimensions approach to organizational behaviour as propounded by Owens (2005). The perspective relates to the need for organizations to seek the development of its workforce by enabling them to not only accumulate knowledge, skills and attitudes but to use such attributes to develop their organizations towards the fulfilment of the organizational goals, missions and visions (Oscar, Mink \& Owens, 2000). The approach thus emphasises the development of what has come to be realised as 'the stock of knowledge the employees have' so that they are motivated to improve their levels of organizational effectiveness (Oscar et al. 2000). The study thus employs this human capital development theory as the lens for viewing the perceptions of SMTs on the continuous professional development of educators in ICT, with a special focus on improving school effectiveness as an aspect of organizational behaviour (Mullins, 2008). It is also in this light that the continuous professional development of educators in ICT in schools is viewed as a coaching practice meant to be on-going in order to improve the realisation of the school's mission and vision. The human capital development theory adopted for this study thus relates to the accumulation of knowledge, skills and attitudes developed by educators in the school as a learning organization (Oscar et al., 2000). Mestry, Harris and Bischoff (2009) also describes CPD as referring to on-going programmes aimed at improving the stock of knowledge employees possess at the time of their recruitment.

The Departments of Education in South Africa's nine provinces has initiated programmes to help and support educators on the acquisition of ICT knowledge and skills. The Guidelines for Teacher Training and Professional Development in ICT are a step towards guiding the development of ICT knowledge and skills for teachers to enhance the educational experiences of learners in the implementation of the National Curriculum Statement and Curriculum and Assessment Policy Statement (Department of Education, 2001). Given the aforementioned initiatives coupled with the demands e-learning, ICT educators in both private and public schools need to consistently upgrade their ICT content knowledge, skills and competencies if they are to adequately promote e-education and it into their teaching and learning.

Drawing from the human capital development model, it is important to note that oganizational leaders such as school principals, members of the SBST, SMTs, heads of departments and senior educators should thus be viewed as coaches who mentor their junior or subordinate staff as part of their strategies for improving school effectiveness just as a coach does in his or her quest to win in a game. Proponents of the human dimensions of organizations (e.g. Meyer \& Marshal 1998; Mintzberg 2002; Oscar et al 2000) concur that developing the human capital through on-going processes of skills development is one of the many strategies available to mentor organizational members towards improved organizational behaviour if the organizational goals are to be optimally achieved. Using the coaching and game metaphor mentioned earlier on, this process is akin to a game plan whereby a coach who desires to win every game would ensure that his or her players are continuously trained, ever-ready and motivated to give their best. In organizations such as schools, this requires team players, educators and members of the SBST, SMTs and administrators to intertwine their organizational behaviour with strategies of team building to ensure each team player is committed to the game plan, which implies improving learner performance through thoroughly preparing educators to effectively tackle their professional roles within the schools they operate. Such programmes constitute the effective professional development of educators (Owens, 2005; Oscar et al 2000). 


\subsection{Conceptualizations of CPD for educators}

In many countries, the role and functioning of schools are changing and so is what is expected of teachers (Desimone et al 2006). Teachers are having to teach in increasingly multicultural classrooms; to place greater emphasis on integrating students with special learning needs in their classrooms; to make more effective use of information and communication technologies (ICT) for teaching; to engage more in planning within evaluative and accountability frameworks; and to do more to involve parents in schools (SMTs). No matter how good pre-service training for teachers is, it cannot be expected to prepare teachers for all the challenges they will face throughout their careers (Oscar et al. 2000). Education systems therefore seek to provide teachers with opportunities for in-service professional development in order to maintain a high standard of teaching and to retain a high-quality teacher workforce (Peters \& Waterman, 2008). As Mestry et al (2009) noted effective professional development should be on-going, include training, practice and feedback and provides adequate time and follow-up support. Successful programmes should involve teachers in learning activities that are similar to the ones they will use with their learners and encourage the development of teachers' learning communities. There is growing interest in developing schools as learning organisations and in ways for teachers to share their expertise and experience more systematically. According to Fullan (2001) the development of teachers beyond their initial training can serve a number of objectives such as to update individuals' knowledge of a subject in light of recent advances in the area; to update individuals' skills, attitudes and approaches in light of the development of new teaching techniques and objectives, new circumstances and new educational research; to enable individuals to apply changes made to curricula or other aspects of teaching practice; to enable schools to develop and apply new strategies concerning the curriculum and other aspects of teaching practice; to exchange information and expertise among teachers and others, e.g. academics, industrialists; and to help weaker teachers become more effective. To examine these issues, Fullan adopts a broad definition of professional development among teachers. He argues that professional development implies activities that develop an individual's skills, knowledge, expertise and other characteristics as a teacher. The definition recognises that development can be provided in many ways, ranging from the formal to the informal. It can be made available through external expertise in the form of courses, workshops or formal qualification programmes, through collaboration between schools or teachers across schools (e.g. observational visits to other schools or teacher networks) or within the schools in which teachers work. In this last case, development can be provided through coaching/mentoring, collaborative planning and teaching, and the sharing of good practices.

Fullan (2001) expands the definition to include the sum total of formal and informal learning experiences throughout one's career from pre-service teacher education to retirement. This study considers the meaning of professional development in the technological age, in the context of ICT use in the classroom. It argues suggests a broader definition of professional development that includes the use of technology to foster teacher growth in their schools as learning organizations. In this sense the teacher professional development programmes go beyond mere training with its implications of learning skills and encompasses a definition that includes formal and informal means of helping teachers not only learn new skills but also develop new insights into pedagogy and their own practice and explore new or advanced understandings of content and resources (Fullan, 2001). This definition of professional development includes support for teachers as they encounter the challenges that come with putting into practice their evolving understandings about the use of technology to support inquiry-based learning (Oscar et al. 2000). Current technologies offer resources to meet these challenges and provide teachers with a cluster of the support that helps them continue to grow in their professional skills, understandings and interests.

In a study to examine whether mathematics teachers in need of continuous content based professional development were receiving it through the continuous professional development programmes initiated in their country, researchers, Desimone, Smith and Ueno (2006) came to the inference that although administrators and policy makers have focussed their energies on the concept of teacher professional development as a quality enhancement strategy, they wondered why professional development in mathematics was not fulfilling its educational role of helping needy teachers. The study by Desimone et al (2006) reviewed the teachers' levels of preparedness to effectively deal with the challenges that needed attention in schools. Their contention was that such teacher professional development tended to serve the needs of teachers who were already in possession of a strong pedagogical content knowledge in mathematics as opposed to novice educators, who needed to be professionally developed. In their views, the continuous teacher development programmes tended to make sweeping assumptions that side-lined the real would-be beneficiaries of the programmes (Desimone et al. 2006). The above implied that the designers of the continuous teacher professional development were not analysing the organizational behaviour and needs of schools objectively enough to cater for the needs of all educators in schools (Oscar et al. 2000). 


\subsection{The role of leadership in the CPD of educators}

Available literature (e.g. Desimone et al. 2006; Mestry et al. 2009; Owens 2005; Stein, Shepard \& Harris 2011) shows that the perspectives organisational members hold about a given phenomenon influence their levels of organisational commitment and role consciousness. This idea is reflected in views expressed by Mestry et al (2009) and Stein et al (2011) in researchers where they found that how a phenomenon is perceived by leaders or the responsible authorities will always have an enormous impact on its value in society. From these views one understands that the organisational behaviour of members is to a greater extent influenced by the views of those responsible for the planning and auctioning the professional development programmes in institutions of learning. The aforementioned study revealed basically five perceptions held by tertiary level ICT educators: e-learning as a tool and equipment, as a facilitator of interaction, as learning, as a reduction in distance and as a collaborate enterprise; determine the course of action followed by these educators (Stein et al, 2011). From the insights in this research it follows that if educators are to realise importance of continuous professional development or improvement in the quality of their teaching and learning in their classrooms and the school system, stakeholders such as the Department of Education, SMTs, SBSTs, educators and policy makers need to build the capacity of the educators to meet these expectations. According to Oscar et al (2000), this will require more than simply allocating additional resources for professional development programmes. It will require an understanding of what teachers must know and do to improve student learning. Most importantly, the process will need a model of teaching and learning that informs all the opportunities provided for teachers to engage in the improvement of their practice over time (Owens, 2005). The above views also generate valuable insights in that the professional learning process for effective schools should have a clear outline of the school's vision for professional learning. It unpacks some of the principles of highly effective professional teaching and learning, which are crucial for effective schools (Desimone et al. 2006). The authors describe the conditions that support the implementation of effective professional development and it is in this sense that the paper can be said to inform the design of teacher learning initiatives at all levels of the system. It reminds us that as educators in a school system, we have a shared responsibility to improve student learning outcomes Department of Education, 2001).

The literature on continuous professional of educators (Desimone et al. 2006; Owens 2005) also shows that the leadership role in an organization is an integral part of all organisational behaviour and development. Leaders at schools, have to provide the necessary action plans to activate professional development programmes, in order to inculcate a culture of effective teaching and learning. It is the leaders, who through the implementation of professional development programmes can achieve the aims and objectives of their schools. Such literature can be viewed as a wakeup call to leaders in educational institutions to ensure that the central part of the practice of improving school effectiveness by making the connection between continuous teacher professional development addresses the key teaching practice demands so that the present generation of students receive the best in their learning and that their learning is not mortgaged against the probability that something good will happen for future generations (Oscar et al. 2000). Improvement should be focused directly on the classroom experience of today's students. This implies bridging the gap between standards and achievement, which can be viewed as the imperative for continuous professional development in education.

\subsection{The impact of CPD on organizational behaviour}

On the question of the influence of teacher CPD on school effectiveness, several scholars (e.g. Peters \& Waterman 2002; Glenn, 2008; Oscar et al. 2000) maintain that there is a positive correlation between these two aspects in that one fosters the other. They are thus mutually constitutive. The educators' competence levels are improved while their level of commitment to the realisation of their organisation's goals is also buttressed (Oscar et al. 2000). From the literature examined in this section, it follows that it is imperative in this $21^{\text {st }}$ century for stakeholders in schools to ensure that educator professional development is taken seriously. This is so because learning and teaching trends are currently undergoing transformations (Desimone et al. 2006). Educators thus need a high level of preparedness to deal with elearning and related aspects if they are to remain relevant to modern day teaching and learning systems (Desimone et al. 2006). Professional development programmes should thus focus on a wider spectrum instead of on just pedagogical or content- based approaches (Mestry et al. 2009).

Several authors (e.g. Desimone et al. 2006; Mestry et al. 2009) maintain that only if educators are professionally developed can schools then become effective in meeting their core business, which is to enhance the development of learner skills and abilities. The major focus of these authors' views is on the value of teacher professional development programmes as a way of enhancing school effectiveness. Mestry et al (2009) for example, draw their argument from the 
Integrated Quality Management Systems (IQMS) and how it can be used as a tool to measure the, individual teacher development needs, in public schools. They examine the policy, the Integrated Quality Management Systems IQMS, which is used as a programme for professional development of teachers in public schools. They question the validity and reliability or effectiveness of the IQMS system by using quantitative research and a sample of five hundred questionnaires to argue over what they view as straight forward situation needing immediate serious attention. Among the key aspects of the professional development of teachers advanced by the aforementioned authors is the view that for a school system to be effective, stakeholders have a shared responsibility to improve student learning outcomes, which is essentially an important product of the CPD of educators in a school (Oscar et al. 2000). For them, the school's stakeholders also have a reciprocal responsibility to provide teachers with extended opportunities to build on what they already know about effective learning and teaching. The process entails creating a positive organizational culture (Mullins, 2008) of teaching and learning; developing teacher morale and improving the role of leadership within the school as a learning organization. It is only when educators develop a sound commitment to their organisational culture that their behaviour and developmental goals can become an important motivator in their course of duty. This view is consistent with that of Guskey (2000), who notes that professionally developed teachers become more effective and efficient in their organizational behaviour. It is in this sense that the continuous professional development of educators is viewed as more than the mere improvement and development of individual teachers. It seeks to improve the performance of the school as a whole (Desimone et al. 2006).

The implications of the literature reviewed in this section for classroom practice are enormous. For example, gets insights on how his or her actions, beliefs, thinking and performance as an educator, contribute to the success or failure of that organisation. One's depth in pedagogical content knowledge, classroom management skills, attitude towards teaching and learning are thus greatly impacted by the organisational culture fostered by the organization's attitude towards CPD (Mullins, 2008). In terms of school effectiveness, one also realises that the effective organisational behaviour of educators in a school can be greatly improved if the school's stakeholders develop positive attitudes towards the CPD of educators.

\subsection{Strategies for improving school effectiveness}

The views expressed in the literature review of this study indicate that new inventions in the teaching and learning environment need to be taken seriously as one of the 21st century imperatives for CPD (Desimone, et al. 2006). To improve school effectiveness for the 21st century, educational stakeholders need to realise the importance of e-learning as a tool for overcoming such learning barriers as reduction in distance between or among learners given the benefits of the World Wide Web or internet (Desimone et al. 2006). Meeting the goals, mission and visions of schools as learning organizations thus requires far more than simply allocating resources such as computers for learners and their educators but also an awareness of the need for capacity building for these educators.

\section{Research Design and Methodology}

A qualitative research design utilising an exploratory case study as the design genre was considered ideal for this research because it allowed the researcher an opportunity to generate in-depth data through probing the participants' lived experiences in the school as a learning organization (Nieuwenhuis, 2012). Cohen, Manion and Morrison (2007) view a case study as an exploration of a specific event or situation in its natural habitat for purposes of capturing the complexity and situational behaviours of the participants. It was in this light that as a researcher, I undertook to investigate the social reality of SMTs on their perceptions of CPD for ICT educators.

\section{Data Collection}

According to Cohen, Manion and Morrison (2002: 44) data collection methods describe the overall techniques and procedures used in the gathering of data. Consistent with the demands of qualitative research, semi-structured individual interviews and observations were used as the instruments for data collection.

\subsection{Semi- Structured individual interviews}

In a research context, an interview method describes a question and answer session between the researcher and the researched (Nieuwenhuis, 2012). For this enabled me to elicit the data on the perceptions of SMTs on the CPD of ICT 
educators in schools. The interviews were held with ICT educators and members of the SMTs and these were audio recorded. Ten participants were interviewed and these comprised 6 ICT educators and 4 members of the SMTS. The latter included the school principal, deputy principal, head of department and a senior educator. Thirteen questions were asked to each interviewee through the use of interview schedule and each interview session was for a duration of thirty minutes in the school's staff room. Drawing on Babbie's (2008:13) contention that in-depth qualitative interviewing relies exclusively on structured and open-ended questions, the interviews followed this technique so as to elicit relevant and indepth data pertaining to the perceptions of SMT on the CPD of the ICT educators.

\subsection{Observations}

Nieuwenhuis (2012) views observation as a tool for looking, seeing, feeling and hearing the participants' views on a particular subject. For this study, an overt observation strategy was adopted. To do this, the researcher sought the participants' informed consent as part of the ethical considerations for the study. He thus explained to them the purpose of the study and the modus operandi it was to adopt. In using overt observation along with individual interviews, the researcher wished to triangulate the data responses to enhance trustworthiness in the study (Hesse-Biber, 2012). The use of running records to capture the observations proved worthwhile in that they helped capture the salient aspects of the data collection process. The recorded data were treated as part of the field-notes constituting some of the units of analysis (Creswell, 2012: 216). The observation made it easier for the researcher to gain insight into the interviewees' views and to develop an amicable rapport with them (Henning, van Rensburg \& Smit, 2004).

\subsection{Population and Sampling}

The site chosen for this study was a public primary school in Johannesburg south, pseudonymously called Glenanda. The school has a population of five hundred and forty five people made up of five hundred pupils and a staff complement of forty five educators. The ages of the latter range from thirty to fifty years. Both educators and learners come from diverse socio-cultural backgrounds. A large majority of learners in this school come from middle to high income families. The school is well resourced with such educational gadgets as computers, data projectors and smart-boards. From the researcher's interaction with the ICT educators, it was apparent that the latter were hesitant to use the computers as teaching and learning tools in the presence of the former because their learners appeared more comfortable with the computers than them. In terms of sampling, a purposive sampling technique was adopted. The sample size came from Glenanda Primary School (pseudonym). The sample size was 10 participants purposively selected on account of either being ICT educators or SMTS in possession of power and authority in the leadership and management matrix of the school administration.

\section{Ethical Considerations}

For the purpose of this study, the following ethical principles were adhered to: informed consent, beneficence, privacy, confidentiality, anonymity, and protection from harm (non-maleficence and voluntary participation (Babbie, 2010: 66). Participants were also briefed on the focus of the study and the objectives. Informed consent was also sought from each of the participants before interviewing and audio recording them. Consent to participate in the study was also obtained through consent letters distributed to the prospective participants as part of the advance protocol. Participants were also sensitised to their rights to privacy, anonymity, confidentiality and trust as well as protection from harm (Henning, van Rensburg \& Smit, 2004:73).

\section{Data Analysis}

The analysis proceeded on a case-by-case basis as described by Nieuwenhuis (2012). For example, every interview transcript was read several times to develop general understanding then more closely to separate each text into meaning units or themes. For each unit, a descriptive theme summarising the experiences the participants recounted was captured. This was followed by interpretative coding to identify salient themes before moving on to the next case. The emerging themes were then clustered into superordinate themes that formed the basis of the thematic analysis, interpretation and discussion of the findings. 


\title{
10. Findings
}

The following themes formed the basis of the discussion of findings: The importance of continuous professional development; perceptions of SMTs on the continuous professional development of educators in ICT; the role SMTs play in the professional development of educators in ICT; how SMTs view the link between continuous professional development of educators and school effectiveness and strategies for improving school effectiveness.

\subsection{The importance of continuous professional development}

The findings of this study highlighted the importance of continuous teacher professional development as an element of organizational motivation. It emerged from the interview proceedings that the accumulation of skills and knowledge by teachers is viewed by members of the SMTs as the accumulation of sufficient knowledge for their work as assets of the school. The responses given by SMTs reflect the imperative nature of the continuous professional development of ICT educators given the impetus ICT has brought into the field of education. This view is evident in the excerpt below.

\begin{abstract}
Mr Makhubele: A teacher who is computer illiterate in this 211st century needs to catch up if he is to function fruitfully in his classroom practice. Nowadays, no teacher can function effectively without knowledge of ICT therefore those who were born and trained before technology (BBT) need to go for in-service training in computer assisted teaching and learning if they are to cope with current trends in teaching and learning.
\end{abstract}

The data also revealed that school leadership is an integral part of continuous teacher professional and organisational behaviour and development. Participants pointed out that ineffective school leaders and SMTs are sometimes detrimental to the continuous professional development of educators in that they thwart the programmes meant to benefit ICT educators in their quest to continuously develop themselves. Instead of providing the necessary action plans to activate professional development programmes in their schools they tend to jealously guard against the resources meant for the continuous professional development of educators in order to be seen as economical in terms of the management of resources. The above findings were a wakeup call to conservative SMTs in educational institutions for them to give the professional development of educators the attention it deserves if they are to help improve school effectiveness. The findings also confirmed that changing the teaching and learning culture in schools as learning organizations should be treated as part of both the human and institutional existence especially in light of ICT inventions and what they can in education. Such findings confirm Blake's (2008:90) assertion that embracing current technological trends in ICT is important in every institution because it makes the organisational members stay abreast with the obtaining global trends in ICT education. The excerpts below captured from some of the participants evidence this.

Participant 1: The first thing ...... make sure they go somewhere

Participant 2: My understanding is to get more skills and knowledge in order to improve the quality and teaching of learners is the way I understand it

Participant 3: It can be done in many different ways...... they can do a lot of reading on their own and discussions can take place with their own colleagues at school.

\subsection{Perceptions of SMTS on the CPD educators}

Despite the main findings showing that the professional development of educators is viewed by SMTS as important for organizational behaviour, the results of this study revealed a dire need for solutions to the professional development of educators especially problems associated with the implementation and planning of professional development programmes for educators. Among the challenges cited by participants (SMTS) were that the participants indicated that there is not enough time during the day to send educators for professional development workshops or INSET programmes. This is because the teachers have many extra- mural (sporting) activities and lots of administrative work to perform in the afternoons, especially in the foundation phase. Furthermore it was noticed that those educators who were professionally developed in terms of acquiring an extended qualification, placed their job requirements second and their studies first. Due to these problems, educators have lost the interest in wanting to be professionally developed. Educators were also reluctant to attend workshops held at the department due to the poor quality of the workshops, the poor facilitation skills and lack of content knowledge, of the facilitators. The excerpts below attest to the above views:

Participant 1: They do a lot of extra mural activities so there is no time in the afternoons to develop themselves 
Participant 2: I do find that, that impacts quite heavily particularly extra- murally where teachers have got lectures to attend

Participant 3: They are simply interested in bettering themselves at the expense of learners to whom they have to attend from $8 \mathrm{am}$ to $4 \mathrm{pm}$.

Members of the SMT understand continuous professional development as vital to the development of any educator. They pointed out that they appreciate educators who seek to improve themselves through part-time studies as opposed to full time ones since the latter would require them to leave learners unattended. This view was evident in the following excerpts:

Participant 4: I believe it is an important aspect of education...... enhances the learning experiences of the child. Participant 1: They don't think of themselves as being lifelong learners

Participant 2: Not for them to develop, but if you think you have a bit more status but also for the children in the classroom to develop.

\subsection{The role of SMT's in the CPD of ICT educators}

It emerged from the data gathered for this study that the role of the SMT is basically to identify educators according to their needs for development and send them for courses for which they are recommended. They ensure the up-skilling of teachers' knowledge takes place, by either sending the educators to workshops or having a mentorship system in place. The SMT works together with the school governing body in ensuring that the funds are provided for these educators to attend professional development workshops. It was for example established that within the foundation phase, a lot of collaboration among educators takes place. The evidence from the below excerpts reflects this view

Participant 3: I think their role is to facilitate curriculum delivery.

Participant 4:I think that the teachers who have good skills in ehm... a field or a learning area, even if they are still trying to better themselves ........ they've got good tips to impart to the younger members of staff to the inexperienced members of staff.

Participant 2: Firstly you have to have a phenomenal mentoring system in place.

Responding to the question of how SMTs prepare for the professional development of educators, the participants claimed they address educators in a staff meeting or within their phases to discuss different ideas on how they can provide professional development opportunities for educators. They then use IQMS scores as a benchmark to identify areas that educators need to be developed in. Another way of planning opportunities for professional development programmes is to do class visits or lesson observations. The educator's strengths or weaknesses are identified and based on the outcome of the class visit, educators are will be sent for specific professional development programmes. The principal looks at senior teachers as mentors, to support the younger teachers. He also creates the opportunity for the development of qualifications. Members of the SMT also work with the SGB to secure a bursary scheme for learnerships. The current planned professional development is the development of ICT skills. These views are reflected in the excerpts below.

Participant 1: The best idea is to is to promote it by a staff meeting", and

Participant 2: We do class visits and that's where we see if they've learnt from going on a course

Participant 3: And where the principal gets involved is to see that those teachers are equipped to deliver what they have to deliver in the classroom. If we identify some-one who is not equipped to do that... it's necessary for those teachers to attend little mini courses to upgrade their skills

\subsection{How SMTS view the interplay of CPD and school effectiveness}

Given that the research questions for this study was on the school management team's perceptions of professional development of educators in the use of ICT in the classroom, the findings of this study revealed that where members of the SMTS value continuous professional development of educators, chances are that they will step up the initiatives to promote the continuous professional development of the educators in their school. On the contrary, where there is no synergy between educators and the SMTS, the educators' ICT skills needs are ignored under the pretext that the school has no funds for such projects. These views lent credence to amongst others, Blake's (2008) assertion that the school management teams have the potential to encourage or discourage the continuous professional development of educators 
if relations are not cordial within their schools.

The study revealed crucial insights on how ICT educators in particular and teachers in general need CPD as an inevitable aspect of professional practice. The participants pointed out that apart from their day to day school activities, they can also make use of extra time and weekends to focus on their professional development strategies. Although the majority of participants concurred that the professional workshops and training provided by the Department of Education (GDE) is of paramount importance, they recommended that such programmes be adequately resourced and be run by experts in the field. They lamented the attitude of SMT especially for not perceiving them as lifelong learners who should be kept abreast with modern trends in ICT education. This finding lends credence to Gray's (2005) assertion that educators should be encouraged to continually study and engage in a life-long career development programmes especially in this era of educational technology.

\subsection{Improving school effectiveness through Teacher CPD}

Although the interviewees provided a very limited knowledge on the use of ICT in teaching and learning, they concurred that its use in the schools is imperative in teaching since it creates a new learning experience for both the educators and their learners. They cited the support given to ICT use in the White Paper 7 on e -Education (2004: 1) and the Guidelines to Teacher Training and Professional Development in ICT (2007:1) that recognise the importance and need for the education system, the teachers and learners to be involved in the digital age. One participant actually pointed out the following in support of his view:

Participant1: The National Department of Education (2007) agrees with this in that, the training of educators in ICT, will enhance the educational experiences of learners and develop life-long learning for educators.

The above views underscore the various ways through which ICT use can be used as a platform for improving school effectiveness. Continuous teacher professional development initiatives such placing greater emphasis on integrating the use of information and communication technologies (ICT) for teaching, engaging more in planning within ICT evaluative and accountability frameworks and doing more to involve parents in schools (SGBs). Schools should thus seek to provide teachers with opportunities for in-service professional development in order to maintain a high standard of teaching and to retain a high-quality ICT teaching workforce. Effective continuous professional development should thus be on-going, include new trends in software, hardware and general practice and feedback in adequate time and follow-up support to improve school effectiveness. Worthwhile professional development initiatives should therefore involve ICT educators in learning activities that are similar to the ones they will use with their learners as this would encourage the development of teaching and learning communities (Lave \& Wenge, 1998).

\section{Conclusion and Recommendations}

From the findings reported in this research paper, the following conclusions are made: if the organizational behaviour of members of staff in a school is to improve, the SMTs need to prioritise continuous professional development programmes particularly in the area of ICT because current technological trends in education make it imperative that ICT educators be constantly developed as a way to build their capacity when working with digital natives in the school and classroom. No school can ignore the importance of current developments in ICT use in the classroom and remain relevant to modern day education. ICT educators must thus be encouraged to undergo continuous professional development if they are to improve their effectiveness in the classroom. In view of these conclusions, the following recommendations are made: SMTS need to create a conducive organizational culture to promote effective continuous teacher professional development. The role of continuous professional development in developing teacher morale needs to be emphasised and be understood by SMTS. Schools should aim at reconstructing an education system that values not just competence in ICT use but also the values of the e-learning technology since today's learners have become digital natives. It is in this light that the study recommends that SMT's need to support the development and use of computer-mediated teaching and learning in appropriate and rewarding ways.

\section{References}

Babbie, E. (2010). The Practice of Social Research. Belmont CA: Thompson

Barrow, R. (2005). Giving back to teachers: A critical introduction to curriculum theory. New York: Routledge 
Blake, C. (2008). The Art of Decisions: How to manage in an uncertain world. New York: Routledge Department of Education (2004), White paper 7. Pretoria: Government Printers

Desimone, L., Smith, T. \& Ueno, K. (2006). Are teachers who need sustained content-focused professional development getting it? An administrator's dilemma. Educational Quarterly, 42 (1): $42-54$

Diale, G. (2010). Motivation in education: Theory, Research and Application. New York: Sage

Cohen, L., Manion, G. \& Morrison, P. (2007). Research in Education. San Francisco: Jossey-Bass

Creswell, J. (2012). The Mixed Method research guide. London: Sage

Fullan, M. (2001). Leading in a culture of change> London: Allen \& Unwin

Glenn, P. (2008). Cross Functional Teams: Working with Allies, Enemies and Other Strangers. San Francisco: Jossey-Bass

Guskey, T. (2000). Evaluating Professional development. New York: Routledge

Henning,E., Smit, B.\& Van Rensburg,W.(2004). Finding your way in academic writing. Pretoria: Van Schaik.

Leedy, P.D.\& Ormrod, M. (2009) Practical Research: Planning \& Design. London: Sage.

Lautenbach, J. (2008). Research methods in practice: strategies for description and causation. South African journal of Education, 23 (2): $38-41$

Lave, J. \& Wenge, W. (1998). Communities of practice: Legitimate peripheral participation. London: Sage

Lichtman, D. (2010). Professional Development in an Educational context. International Journal of Educational Sciences, 32 (2):241-6

Mestry, R., Hendricks,M. \& Bishoffs, T. (2009). Perceptions of teachers on the benefits of teacher development programmes in one province in South Africa. South African journal of education, 29 (4): 141-147

Meyer, M. \& Marshal, W. (1998). Environments and Organizations. San Francisco: Jossey-Bass

Mintzberg, H. (2002). The Structuring of Organizations. London: Prentice Hall

Mullins, R. (2008). Organizational theory, Design and Change. London: Methuen National Department of Education (2007). Pretoria: government Printers

Mutekwe, E. \& Modiba, M. (2014). Perceptions of High teachers and Students on the extent to which the curriculum followed correlates with career aspirations and choices. The Anthropologist, 17 (2):577-589

Mutekwe, E. (2014). Unpacking the role of student feedback as a basis for metacognition and mediated learning experiences: A sociocultural perspectives.

Journal of Education and learning (Edu learn), 8 (4): 221-229

Nieuwenhuis, J. (2010). Analysing qualitative data (pp. 72-80). In K. Maree (Ed.), First Steps in Research. Pretoria: Van Schaik.

Oscar, M., Mink, P. \& Owens, R. (2000). Developing High Performance People: The Art of coaching. Reading: Longman

Owens, R. \& Valesky, TC. (2005). Organizational Behaviour: Adaptive leadership and school reform. London: Sage

Peters, T. \& Waterman, H. (2008). In search of Excellence: Lessons from America's Best-Run Companies. New York: Harper \& Row

Sapsford, R. \& Jupp, V. (2006). Data collection and Analysis. London: Sage

Stein, S., Shephard, K. \& Harris, I. (2011). Conceptions of e-learning and professional development for e-learning held by tertiary education in New Zealand. British Journal of Educational Technology, 42 (1):145-165

Yin, R. (2009). Case study research, design and methods. Newbury Park: Sage 